\title{
Spanish-Language Home Visitation to Disadvantaged Latino Preschoolers: A Means of Promoting Language Development and English School Readiness
}

\author{
Virginia Mann \\ Department of Cognitive Sciences, University of California, Irvine, USA \\ Email: vmann@uci.edu
}

Received 16 January 2014; revised 16 February 2014; accepted 23 February 2014

Copyright (C) 2014 by author and Scientific Research Publishing Inc.

This work is licensed under the Creative Commons Attribution International License (CC BY). http://creativecommons.org/licenses/by/4.0/

(c) (i) Open Access

\section{Abstract}

This study reports five years of a school readiness intervention called "HABLA" (Home Based Activities Building Language Acquisition), designed to increase and enrich speech and literacy activities in the homes of economically and educationally disadvantaged Latino families with children between the age of 2 and 4 . A team of trained home visitors provided two years of a 23-week program of visitation in which they met with parent(s) and child twice weekly. Both years presented a Spanish language adaptation of the parent-child home program model; home visitors provide intensive modeling and coaching of non-directive Spanish language use, conversation, and literacy activities. Administration of the PLS-3 in Spanish at the onset and culmination of each year of the program indicates significant increases in receptive and expressive language for each year of visitation (7.8 standard points for the first year, 4.4 for the second) with effect-size $r$ ranging from .24 to 42. Participants had significantly improved their levels of oral Spanish skill and scored much higher than a comparison group of non-treated. A subset of graduates of the two-year program was tested as kindergarteners; they showed a continued advantage over a comparison group of 18 peers who had not received the intervention. For the graduates, both their Spanish PLS-3 scores and English PLS-4 scores were significantly higher, and their parents reported a continued effort to provide literacy experiences at home. The HABLA participants also showed a clear advantage for an English language test of phonological awareness, one of the strongest predictors of school success.

\section{Keywords}

Component, School Readiness, Home Visitation, Spanish ELL 


\section{Introduction}

During the early years of their lives, children in affluent and poor families experience a dramatic difference in exposure to speech (Hart \& Risely, 1995). On average, those living in poverty hear 300 fewer words per hour and this culminates in a 30 million-word deficit by the time children enter kindergarten. Tied to this deficiency in spoken language, exposure is a commensurate deficiency in children's speech that directly relates to the style, quality and diversity of their parent's language (Hart \& Risley, 1995). As speech skills are key ingredients in school success (see Duncan et al., 2006; Mann, 1998, Snow, Burns, \& Griffins 1998), early deficiencies in the speech environment, if left unheeded, may cascade into educational disadvantages and a tragic loss of social capital.

Because the difference in the speech environment between advantaged and disadvantaged children begins so early in their lives, effective intervention must also begin early. An ideal intervention should increase the quality and quantity of parent to child language and should involve shared activities that can become self-sustaining after treatment ceases. The intervention should be home-based, and even if the children are to be English language learners once they begin school, the intervention should target the language of the home since that is the language the parent is most capable of delivering with appropriately rich vocabulary and grammar. Prompted by these considerations, we have developed a home-based intervention program to enrich the Spanish home language and literacy environments of poor Latino children. It is based on the highly successful Parent Child Program (Levenstein, Levenstein, Shiminski, \& Stolzberg, 1998).

\section{Intervention in the Home Language}

The participants in this study are native speakers of Spanish whose language and literacy environments in the home are likely to be weak and a limit on the development of children's language. Their academic achievement is likely to suffer from the combined influence of SES, parental education, parental language style and the challenges of ELL; they live in conditions of economic disadvantage (the average family income for the present study is \$19,000), low maternal education (average maternal education a predominance of directive language use (Laosa, 1982). They live in homes where Spanish is dominant and English is a second language at best (the 2000 census registered our treatment site as having the largest concentration of ELL speakers of Spanish).

Families with low-income, low maternal education, and low proficiency in the English language experience greater hardships, have limited access to resources, and must cope with higher stress levels, all of which diminish the likelihood of their children's school success (Raver \& Knitzer, 2002; Farver, Xu, Eppe \& Lonigan, 2006), As reviewed by Duursma, Romero-Contreras, Szuber, Snow, August, \& Calderon (2007), poor, urban, minority, non-English speaking children, particularly those who speak Spanish, have difficulty learning to read and their achievement gap widens as the children progress through elementary school. Both early on and throughout their time in school, Latino children are twice as likely to read below level as European-American children (Kao \& Tienda, 1995). The urban school district of concern to this study embodies these observations: it serves a majority of Latino children living below the poverty line , and the students achieve scores in the lowest deciles in the state (API of 3 or lower) where schools in less Latino-dense, more affluent neighboring cities score in the upper deciles (API of 7 or higher).

When intervention and outreach target K-12 students in schools or after school programs, they necessarily operates in English, as that is the language of education. However, when intervention and outreach choose early childhood enrichment it is best done in the homes and in the home language. Spanish is the home language of the most disadvantaged children in our geographic area (e.g. Southern California) and in the country at large. When Spanish monolingual children enter school they are expected to matriculate into English. Yet their primary language or "mother tongue" is a scaffold on which to build English matriculation and personal and educational development. Baker (2000), Cummins (2000), Skutnabb-Kangas (2000) and Figuerdo (2006) have each reviewed evidence to the effect that children who come to school with a solid foundation in their mother tongue develop stronger literacy abilities in the school language than those who do not. In Cummins view, in particular, parents and other caregivers (e.g. grandparents) who spend time with their children and tell stories or discuss issues with them in a way that develops their mother tongue vocabulary and concepts have children who come to school well-prepared to learn English and to succeed educationally. This suggests that children's knowledge and skills transfer across languages from the mother tongue they have learned in the home to English in school.

The intervention employed in this study is modeled after the Parent Child Program and is delivered by a cadre 
of students, AmeriCorps members and para-professionals. All are trained both pre-service and in-service, all are mentored by university faculty and by specialists in early childhood education. Together they delivered a curriculum whose goal was to enhance primary language development though shared reading, language play and developmentally appropriate activities involving the parent and the child.

The Parent Child Home Program (PCHP) began 1960's, when Levenstein and her colleagues began to offer language and literacy remediation in the homes of disadvantaged English speakers. These researchers have since then reported on their program's success as a facilitator of academic achievement in early grades and beyond (Lazar \& Darlington, 1982; Kamerman \& Kahn, 1995; Levenstein, Levenstein, Shiminski, \& Stolzberg, 1998). PCHP's stated goal is to help parents discover their role as a child's first and most important teachers. It helps parents to increase the home literacy environment and to enrich spoken skills. The program consists of two years of intervention beginning when the child is approximately two year of age; each year consists of 23 weeks of home visits with two 30-minute visits per week The stated goal of the PCHP is to prepare parents to actively participate in their children's education by focusing on 6 stated objectives: 1) verbal interaction, 2) in the home, 3 ) in the primary language of the home, 4) with methods easily learned, 5) using books and toys that stay in the home and 6) with attention to measurable outcomes that are assessed throughout the program and beyond. Studies of children in English-speaking homes who have received the PCHP show that treated children enter school ready to learn and perform at or above national norms on standardized tests in first grade (Levenstein, Levenstein, \& Oliver, 2002) and throughout elementary school. They graduate from high school at rates equal to those of middle class students (see Levenstein et al., 1998).

In adapting the PCHP methods to our Spanish-speaking clients, we used the tenents of the PCHP. To make the curriculum as advantageous as possible, we chose our curriculum of books, toys and activities to underscored the eight language and literacy activities recommended by The National Reading Panel. These consist of using language in conversation, listening and responding to stories read aloud, listening to the sounds of spoken language, reading often, learning and using new words, understanding what is read, recognizing and naming the letters of the alphabet and connecting sounds to letters to figure out the "code" of reading. The first six NRP activities were used throughout the two-year program; the final two alphabet-oriented activities were introduced in the second year. As a measure of program outcome, we have tracked expressive and receptive Spanish language skill at baseline and at the completion of each year of treatment. For a sample of children who completed both years of the program we have also measured parents' reports of home literacy activities, and children's Spanish and English language skills and phonological awareness in the kindergarten year.

As the National Reading Council (2001) acknowledges, there is widespread recognition and support of the view that early language intervention can enable children to enter school with the language skills needed to succeed. Such language intervention is especially warranted in the case of children from disadvantaged economic backgrounds, given Hart and Risley's (1995) observations. Children in low SES families are at increased risk for developing both deficient language processing skills (Honig, 1982; Walker, Greenwood, Hart, \& Carta, 1994) and deficient phonological awareness (Nittrouer, 1996). According to some, their learning of language is constrained by the low values placed upon language in most low-SES sociolinguistic communities (Purcell-Gates, 1995) as well as by parental input that is more directive and immediate (Laosa, 1980, 1982). Lower SES homes are less likely to offer such important home literacy behaviors as shared reading, children's reading materials and age of onset of shared reading (Lonigan, 1994) and the quality of parent to child language can also be influenced of ethnicity, gender and maternal language upon literacy experience (Gauvain, Savage, \& McCollum, 2000).

The present study's goal was to provide early intervention and mitigation of the educational disadvantage prevalent in our environment. The program was named "HABLA", an acronym for "Home-based Activities Building Language Acquisition” which is also the Spanish imperative for "speak!” HABLA's implementation and adaptation of the PCHP targeted the PCHP stated objectives and the NRC recommendations for early reading and school success. Over its first five years of existence, HABLA recruited families with children aged 15 to 30 months to enter a two-year program in order to better prepare their children for school.

At the onset of treatment and at the end of each of the two 23 week programs of home visits, all participants received a measure of outcome, the Spanish PLS-3, which served as a test of expressive and receptive speech. To determine whether the HABLA program sustained its post-treatment gains in Spanish and translated these into an advantage for school success in English, a subset of children who had completed HABLA were evaluated as kindergarteners and compared to a group of untreated peers attending the same school and preschool. 
The bases of comparison were parental report of home involvement, English and Spanish oral language skills and English and Spanish phonological awareness.

\section{Method}

\subsection{Participants}

Participants were recruited through family resource centers, flyers distributed in local clinics, schools, faith organizations and by word of mouth. The program was also featured once in the local Spanish language newspaper and three times on public television, with contact information was provided in each case. All participants were required to be economically disadvantaged (maximum income of $\$ 30,000$ for a family of 5 or more), educationally disadvantaged (maximum education, 11 years) and to be native speakers of Spanish whose parents used Spanish in the home. Children served with the informed consent of their parents who were also required to sign a consent form and a pledge to be present and involved in every home visit. The applicants ranged in age from 12 to 59 months; it was our experience that parents applied to the program even when their children fell out of the age range (children aged 18 - 42 months) we had posted. All children were assessed and their data help to provide a baseline of Spanish skills for the population. Out of an applicant pool of 612 (52.6\% male), 537 children met the age criterion and were invited to participate in the two-year HABLA intervention. Five children younger than 18 months were put on a wait list, 70 children 42 months and older were given the option of participating in a foreshortened version of the program which will not be reported here.

Towards the end of the study, we had access to a group of HABLA graduates and a group of untreated peers, all of whom had attended a state preschool program and were currently enrolled in a public school kindergarten. Tracking children into kindergarten proved difficult because there are many schools in the area, kindergarten is optional and the need for affordable housing leads many of our participants to move outside of the area. 38 kindergarteners were tested in the winter of the school year; the average ages of HABLA graduated and the untreated peers were 65.6 mo. and 64.0 mo, respectively, and there were 9 girls and 10 boys in the treated group and 9 and 10 in the untreated group. All served with the written consent of their parents, who also completed a home language and reading questionnaire.

\subsection{Materials and Procedure}

The HABLA curriculum: The curriculum consisted of 46 weeks of home visitation, divided into two programs of 23 weeks each. The first program was given at program entry, and the second program was given approximately one year later. Each program lasted about 7 months. Each week of each programs consisted of two visits: one for presentation of a book or toy that remains permanently in the home. Toys and books were chosen for their ability to promote language between parent and child. The same trained home visitor worked with the family for a minimum of one 23 -week program and in $70 \%$ of the cases where children received both programs. In the first 23 weeks of visitation (e.g. the first year of service), the focus was on picture books and materials that emphasized colors, shapes, numbers, animals and common objects as well as basic Spanish grammar and vocabulary. The second set of 23 visits (e.g. the second year) expanded these themes with longer more complex stories, memory activities and the introduction of activities featuring letter names and sounds. The curriculum for each year involved a set order of books and toys chosen to be developmentally appropriate and interrelated. Books and toys alternated and each was provided with a guide sheet that listed the concepts it featured and activities for the parent to do with the child in order to encourage rich language use between parent and child. All materials remain with the family permanently; the books and all instruction are in the language of the home (Spanish and English are both available)) and were chosen to bridge the gap between preschool and home.

The Home visits: During the initial visit each week the home visitor follows a set of specific guidelines to use the featured book or toy to interact with the child, the instructions for books incorporated the principles of dialogic reading (Arnold, Lonigan, \& Whitehurst, 1994; Lonigan \& Whitehurst, 1998) and shared its focus on building children's knowledge of print as well as on interactive oral language use. The instructions for toys and games focused on expressive language and vocabulary expansion as well as upon categorization, comparison and memory. Home visitors are taught to coach the parent and child together and to model the verbal interaction and parenting techniques that can occur through reading and educational play. A tip sheet is left for parents to follow, and the parent and child are coached to use the new book or toy for the next several days with the goal of 
spending at least thirty minutes each day. That same week, two to four days after the initial modeling visit, a second visit occurs. At this time the home visitor assesses parent and child behavior and their ability to sustain verbal play. He or she also provides further coaching and modeling as necessary, and instructs the parent and child to continue to use the toy or book for thirty minutes each day until the next visit. Over time these bi-weekly visits enable the parent to learn how to initiate and sustain the reading and play activities that offer the types of language interaction required for optimal mental development.

Home Visitors: Home Visitors included UCI students, AmeriCorps members and members of the community who were recruited with flyers, course listings and by word of mouth. The requirements for becoming a home visitor were based on the long history of the PCHP approach (Levenstein et al., 1998), HABLA added the additional requirement that all visitors be bilingual in Spanish and English and culturally compatible with the Latino clientele they were to serve. Home visitors were trained by the director and the site managers who had formal PCHP training as well as extensive experience with the assessment and education of preschool children and parent education. The home visitors were trained for 16 hours before their first visit and required to attend twohour weekly in-service training sessions thereafter. They were also individually supervised in the home at various points during the delivery of services, and client satisfaction is regularly monitored. Students served between 1 and 3 families per week, AmeriCorps members and paraprofessionals saw between 6 and 10 .

\subsection{Measures of Treatment Effect}

The Preschool Language Scale (PLS): The site managers administered the PLS-3 in Spanish to all participants at three points in time: program intake, the end of the first year of treatment, and the end of the second year. At the time that this study began, the PLS-3, Spanish Edition (Zimmerman, Steiner, \& Pond, 1993) was the only version available; for consistency, that version was used throughout testing. The PLS is favored in assessment of Head-Start programs (see Kaiser et al., 2000) as well as in longitudinal studies of preschool predictors of reading (see Chaney, 1998) and in clinical and educational settings more generally (see Zimmerman \& Castilleja, 2005) It had the virtue of being available in both English and Spanish, though the Spanish version is not standardized owing to the relatively small sample size $(N=181)$ used in the validation. Zimmerman et al.'s (1993) validation sample of children for the Spanish version yielded "standardized" scores that averaged 90 instead of 100, and an SEM of 15. In that sample the raw scores of Spanish speaking children had begun to fall behind those of the English speakers by 18 months of age.

Kindergarten testing: Kindergarten testing was administered by two trained research assistants who were familiar with the HABLA program but who had not worked with any of the children involved in the assessment. The PLS: For the 38 children who participated in the kindergarten study, the PLS-3 in Spanish was used in the winter but the PLS-4 in English was used in the spring. Use of the newer PLS-4 addresses some of the ceiling effects that could arise in the testing of older subject and the problem of inadequately normalized scores for Spanish (Zimmerman, Steiner, \& Pond, 2002, Zimmerman \& Castilleja, 2005), and also provides a measure of the effect of HABLA on children's matriculation into English.

Phonological awareness: Materials for this assessment were adapted from those used in the preschool studies of Foy \& Mann (2001, 2003), and consisted of two parts: a test of rhyme awareness and two tests of phoneme awareness. Rhyme awareness materials included an 8 item odd-man out rhyme recognition using pictures of common objects and a rhyme production task in which the children were asked to say "what word rhymes with

” for five trials consisting of common words (e.g., hop). Words and non-words were scored as correct as long as they rhymed with the target word.

Phoneme awareness materials were prepared in Spanish and English, and consisted of practice trials and test items for each of four subtests assessing phoneme judgment and phoneme deletion in both initial and final positions. The subtests each consisted of two practice items and five test items. The tests were administered in standard order: phoneme judgment, phoneme deletion, and phoneme substitution.

The scoring followed Foy and Mann (2003): Rhyme awareness was measured as the total of responses on the two rhyme tests, as our primary interest was in the comparison between treated and untreated children, we used Z-transforms so that Spanish testing would not be penalized by the earlier time of testing. For phoneme awareness, phoneme judgment was considered a separate variable from phoneme deletion but we combined z-transforms of the initial and final segment parts within each of these two tasks as the interest was not so much in the effects of age as in the existence of any differences between the two groups in each of the two languages. 
Parent survey: A subset of items from Seneschal, Le Fevre, Thomas and Daley (1998) as used in Foy and Mann (2003) were incorporated into a short survey that was made available in Spanish and in English and was given to the parents of the children who participated in the kindergarten assessment. The questions appear in Appendix B; they concern the literacy environment of the family (books available, child's interest in books, frequency child is read to, parental intent to teach).

\section{Results}

\subsection{Rates of Completion and Attrition}

A high attrition was anticipated due to the highly mobile nature of the population, which is economically challenged and experiencing an eastward migration towards affordable housing as well as immigration challenges. It was our experience that families were often forced to move at short notice and that some were forced to return to Mexico. In the snapshot of time that this study captures (e.g. January 2001 to January 2006) 537 children between 18 and 42 months were offered the two-year program of treatment. At the time of analysis, data from 393 were available for one year of treatment, of whom 183 had completed the full two-year program. 181 had dropped after one year and 29 were in the process of receiving program two; 89 children were still in program one and 55 had dropped during the first program. We estimate attrition of participants at some point during the full two-year program to be approximately $33.7 \%$, but that $89.4 \%$ of the participants had been able to finish at least the first year of the program.

A series of t-tests revealed very little difference in the demographics of children who completed the full twoyear program compared to those who dropped within or after one year. The three groups appear statistically equivalent with respect to gender, PLS-3 baseline, parental education and income. The only significant difference to emerge concerned the type of household: $36 \%$ of those who dropped the program came from a household headed by a single mother, compared to $28 \%$ of those who continued for the whole program $(t(321)=1.91$, $p<.05)$.

\subsection{The PLS-III in Spanish at Intake and after Each Year of Treatment}

Intake: The PLS-3 was given to all 612 children who applied to the program, whether or not they were in the right age range to begin the study (e.g. two-to-three years of age). The mean "standardized" PLS-3 score for the full cohort of children was 91.7 for auditory comprehension and 89.4 for expressive communication, with standard deviation 13.6 in both cases. As a group, the children were equivalent to those seen in Zimmerman et al.'s (1993) validation sample, which had yielded means of 89.9 and 90.0 for receptive and expressive measures, respectively. In our sample, mean auditory comprehension score was slightly but significantly higher than that of the validation sample, $t(611)=3.02, p<.003$, but the expressive measure was statistically equivalent. Children's average age was 33 months at the time of testing, but age varied between 18 months and 59 months and bivariate correlations showed that age was significantly and negatively correlated with standard receptive skill, $(r(612)=-.277, p<.000$, standard expressive skill, $r(612)=-.110, p<.005$, and the standard total score, $r(612)$ $=-.213, p<.000$. The older children tended to do less well on the PLS-3 relative to what is expected from the English norms and the validation sample. A similar result had been noted in the validation sample (Zimmerman et al., 1993), it may in part be due to the PLS-3 having been created as a Spanish translation of English instead of as a true test of Spanish. Of the 612 children applying to the program, 70 children were 42 months or older. They were too old to be given the treatment program reported in this paper. Their mean age was 46.6 months $(s t d=5.74)$, mean standard Spanish receptive PLS-3 score was 85.87, and mean standard expressive was 86.79. Both of these scores were significantly below the average achieved in the validation sample, $t(69)=-3.37$ and -2.39 , respectively, $p<.02$.

For analyses of outcome, we concentrated on 537 children who were offered the HABLA intervention and whose parents gave written consent. These "treated" children were divided into two cohorts according to the age when they began treatment: those below 30 months (children within six months of being two) and those between 30 and 42 months (children within six months of being three). Each cohort is discussed below. Prior to the start of their HABLA treatment, the treated children had average receptive and expressive scores of 92.47 and 89.88, respectively. Their receptive scores were slightly higher than the validation average (2.5 points, $t(326)=4.15, p$ $<.000$ ) and the expressive scores were equivalent to the validation average. 
Treatment effects of the first year of the program: A total of 393 children completed at least one year of the program at the time of analysis. Their data appear in Table 1 (a) and Table 1(b), separated according to the age at which children entered the program (children younger than 30 months compared to those 30 months or older). A 4-way between groups ANOVA revealed a main effect of the first year's treatment, $F(1,385)=97.263$, MSE $=22077.76, p<.000$; children had gained an average of 7.8 standard points between intake and the end of the first year's treatment. There was also a main effect of the age at entry $F(1,385)=18.28$, MSE $=9069.41, p$ $<.000$ ); the younger cohort had averaged scores that were 5 points higher than the older cohort. The gains were greater for the older children, who had started with lower scores, $F(1,385)=7.868, M S E=1970.55 p<.003$. There was a main effect of subtest, $F(1,385)=37.50, M S E=2065.45, p<.02)$; receptive scores averaged 3 points higher, and two-way and three-way interactions revealed this tended to be greater among the younger cohort, $F(1,385)=7.86, M S E=433.11, p<.005$, and greatest at intake, $F(1,385)=19.29, M S E=865.12, p$ $<.000$, especially for younger participants, $F(1,385)=9.78, M S E=439.08 p<.002$. There was a marginal effect of gender, $F(1,385)=3.67, M S E=1820.70, p<.056$ reflecting a 2.2 point advantage of the female participants, but this did not interact with any of the other variables. There were no other interactions and no effective difference between children who continued on to the full two-year program and those who did not.

In summary, pre- treatment scores had been close to the validation norm for expressive and 2.5 points higher for receptive, $t(392)=3.88, p<.0001$. At the end of the first year's treatment both receptive, $t(392)=12.61, p$ $<.000$, and expressive, $t(392)=10.61, p<.0001$ language measures gained between 7 and 10 points with the younger children maintaining a persistent advantage on PLS-3 scores.

Treatment effects for the full two-year program: At the time of analysis, 183 of the participants had completed the full two-year program. Their results appear in Table 2(a) and Table 2(b), as a function of age at entry. A GLM revealed a significant main effect of the second year of treatment, $F(1,179)=21.57, M S E=3502.44, p$ $<.000$; between the first and second year, children had gained an average of 4.4 points. There was once again, a significant effect of entry age, $F(1,179)=12.68, M S E=6982.45, p<.000$; those who started below 30 months averaged 6.2 points higher than those who started between 30 and 42 months, and this pervaded into the second

Table 1. (a) Mean standard scores (and std deviation) on PLS-3 in Spanish: Effect of first year HABLA treatment on cohort of children age 15 to 30 months; (b) Mean standard scores (and std deviation) on PLS-3 in Spanish: effect of first year HABLA treatment on cohort of children aged 30 to 42 months.

(a)

\begin{tabular}{|c|c|c|c|}
\hline Time of Evaluation & Expressive & Receptive & Mean age (std) \\
\hline Program entry $N=153$ & 91. (1.07) & $97.99(1.10)$ & 26.38 (2.15) months \\
\hline End of First Year N = 153 & $99.98(1.30)$ & $100.81(1.21)$ & 33.54 (3.76) months \\
\hline \multicolumn{4}{|c|}{ (b) } \\
\hline$\underline{\text { Time of Evaluation }}$ & Expressive & Receptive & Mean age (std) \\
\hline Program entry $N=240$ & $86.7(.88)$ & $88.49(.86)$ & 34.29 (3.12) Months \\
\hline End of First Year N = 240 & $97.31(1.04)$ & $98.16(.97)$ & 40.64 (3.39) Months \\
\hline
\end{tabular}

Table 2. (a) Mean standard scores (and std deviation) on PLS-3 in Spanish: effect of second year HABLA treatment on children age 15 to 30 months; (b) Mean Standard Scores (and std deviation) on PLS-3 in Spanish: effect of second year HABLA treatment on children aged 30 to 42 months.

(a)

\begin{tabular}{cccc}
\hline Time of Evaluation & Expressive & Receptive & $\underline{\text { Mean age (std) }}$ \\
\hline End of First Year $\mathbf{N}=\mathbf{8 2}$ & $102.02(1.59)$ & $103.73(1.46)$ & $33.41(4.08)$ Months \\
End of Second Year N = 82 & $105.87(1.60)$ & $106.31(1.61)$ & $44.99(4.18)$ Months \\
\hline
\end{tabular}

(b)

\begin{tabular}{cccc}
\hline Time of Evaluation & $\underline{\text { Expressive }}$ & $\underline{\text { Receptive }}$ & $\underline{\text { Mean (std) }}$ \\
\hline End of First Year $\mathbf{N}=\mathbf{1 0 1}$ & $95.02(1.44)$ & $95.91(1.32)$ & $40.95(3.37)$ months \\
End of Second Year $\mathbf{N}=\mathbf{1 0 1}$ & $101.25(1.45)$ & $100.91(1.45)$ & $52.02(4.14)$ months \\
\hline
\end{tabular}


year of the program There was no difference between the two subtests and all other interactions were not significant, save for a significant effect of gender, $F(1,179)=4.85, M S E=2668.54, p<.03$, reflecting a 3.8 point advantage among the female participants. All scores were significantly greater than the validation average ( $p$ $<.000)$. Paired-t tests indicate that the children had achieved significant gains each year of the program. After the first year, receptive and expressive averaged gains of 6 and 8 standard points, respectively, $t(182)=4.55$ and $6.83, p<.000$, between the first and second year receptive and expressive averaged gains of 6 and 8 and standard points, respectively, $t(182)=4.54$ and $6.83, p<.0001$.

To summarize, the PLS testing reveals a significant effect of the program, for each year of the program. There is also a significant advantage for children who entered before they were 30 months of age. These children start with higher scores and maintain an advantage. Girls tend to perform at higher levels but this does not interact with the treatment effect. There is also a tendency for children to have lower expressive scores at the start of treatment and for expressive to equal receptive as a consequence of treatment. To put these results in terms of treatment effects, we computed Cohen's $d$ and treatment-effect $r$. For children completing one year of the program there are medium treatment effects for receptive scores: Cohen's $d=.4865$, effect-size $r=.2365$, and for expressive: Cohen's $d=.6638$, effect-size $r=.3150$; for the difference between the first and second year's treatment, there are small treatment effects for receptive scores: Cohen's $d=.2670$, effect-size $r=.1393$ and expressive Cohen's $d=.3592$, effect-size $r=.1768$, for the entire two years program, there are medium effects for receptive Cohen's $d=.6518$, effect-size $r=.3099$ and a large effect for expressive Cohen's $d=.9084$, effect-size $r=.4136$.

\subsection{Kindergarten Testing in Spanish and English}

PLS: We began our evaluation of kindergarten effects by looking at PLS results for the HALA graduates as compared to untreated classmates. The scaled PLS-3 had been administered in Spanish in the winter and the scaled PLS-4 in English had been administered in the spring. The results are shown in Table 3 as mean scores for each group at each time of testing. An ANOVA that considered language (Spanish, English), subtest (expressive, receptive) and treatment group (HABLA, control) revealed a significant effect of group, $F(1,36)=$ 4.806, $M S E=1113.57, p<.05$ : the HABLA-treated children had higher scores, an advantage of 4.4 points, on average. The advantage is seen in Table 4, where it may also be seen that there was a significant effect of the type of subtest, $F(1,36)=18.02, M S E=1360.934, p<.0001$ : performance in kindergarten was superior on the tests of expressive language, more so for Spanish than for English $F(1,36)=33.349, M S E=1830.255, p<.0001$, and strongest among the HABLA graduates, $F(1,36)=33.349, M S E=423.031, p<.0001$. The untreated children had achieved scores at the standard norm on the PLS-3 Spanish expressive but were significantly lower than the expected norm on the Spanish receptive $\mathrm{t}(18)=-3.75, p<.001$, English receptive $t(18)=-2.34, p<.03$ and English expressive test $t(18)=-3.82, p<.001$. In contrast, the treated children were at the norm on the Spanish receptive test, the English receptive test and the English expressive test and were significantly above the norm on the Spanish expressive test $t(18)=3.27, p<.01$.

Computation of treatment effects indicated medium effects on Spanish receptive, Cohen's $d=.5743$, effect-size $r=.2760$, minimal effects on Spanish expressive, Cohen's $d=0.0488$, effect-size $r=.0244$, medium effects on English receptive scores, Cohen's $d=.6393$, effect-size $r=.3045$ and minimal effects on English expressive, Cohen's $d=.1096$, effect-size $r=.0547$.

Rhyme awareness: Using the z-transforms of scores computed separately for Spanish and English for each component of the rhyme awareness tests, we computed an ANOVA for group, language and type of test (judgment, production). The results, as summarized in Figure 1, revealed that HABLA graduates averaged higher scores, $F(1,36)=5.839, M S E=5839, p<.021$, but that no other effects or interactions were significant. Computation of treatment effects indicates medium effects for Spanish Cohen's $d=.4622$, effect-size $r=.2252$,

Table 3. Mean (std dev) standard scores on PLS-3 in Spanish and PIS-4 in English: effect of HABLA 2 year treatment on kindergarten performance.

\begin{tabular}{ccccc}
\hline Treatment group & Spanish Expressive & Spanish Receptive & English Expressive & English Receptive \\
\hline HABLA & $108.1(12.60)$ & $91.9(10.25)$ & $97.9(12.91)$ & $96.0(13.70)$ \\
Control & $100.15(14.77)$ & $91.4(10.26)$ & $90.0(11.78)$ & $94.6(11.83)$ \\
\hline
\end{tabular}


Table 4. Pearson two-tailed correlations between kindergarten measures.

\begin{tabular}{|c|c|c|c|c|c|c|c|c|c|c|}
\hline & Sp recept. & Sp express. & Eng recept. & Eng. expr. & Sp rhyme & $\begin{array}{l}\text { Sp. p. } \\
\text { judgm }\end{array}$ & $\begin{array}{l}\text { Sp. p. } \\
\text { manip. }\end{array}$ & $\begin{array}{l}\text { Eng. } \\
\text { rhyme }\end{array}$ & $\begin{array}{l}\text { Eng. p. } \\
\text { judg. }\end{array}$ & $\begin{array}{l}\text { Eng. p. } \\
\text { manip. }\end{array}$ \\
\hline Spanish receptive & 1 & $* *$ & & & & & $*$ & & & \\
\hline Spanish expressive & $.530^{*}$ & 1 & & & ** & * & * & & & \\
\hline English receptive & .206 & .151 & 1 & $* *$ & & & & ** & ** & $* *$ \\
\hline English expressive & .019 & .183 & $.620^{*}$ & 1 & & & & * & & $* *$ \\
\hline Spanish rhyme & .212 & $.313^{*}$ & .122 & .139 & 1 & ** & $* *$ & & & \\
\hline Spanish p. judgment & .235 & $.244^{*}$ & .211 & .023 & $.359^{* *}$ & 1 & ** & * & ** & * \\
\hline Spanish p manip. & $.263^{*}$ & $.266^{*}$ & .026 & .064 & $.501^{* *}$ & $.446^{* *}$ & 1 & & & $* *$ \\
\hline English rhyme & .002 & -.032 & $.500^{*}$ & $.333^{*}$ & .105 & $.355^{*}$ & .161 & 1 & ** & $* *$ \\
\hline English p. judgment & .071 & .182 & $.458^{*}$ & .069 & .192 & $.532^{* *}$ & .238 & $.627^{* *}$ & 1 & $* *$ \\
\hline English p. manip & .197 & .237 & $.525^{*}$ & $.407^{*}$ & .309 & $.325^{*}$ & $.417^{* *}$ & $.426^{* *}$ & $.465^{* *}$ & 1 \\
\hline
\end{tabular}

Note: ${ }^{* *}$ Correlation is significant at the 0.001 level (2-tailed); ${ }^{*}$ Correlation is significant at the 0.05 level (2-tailed).

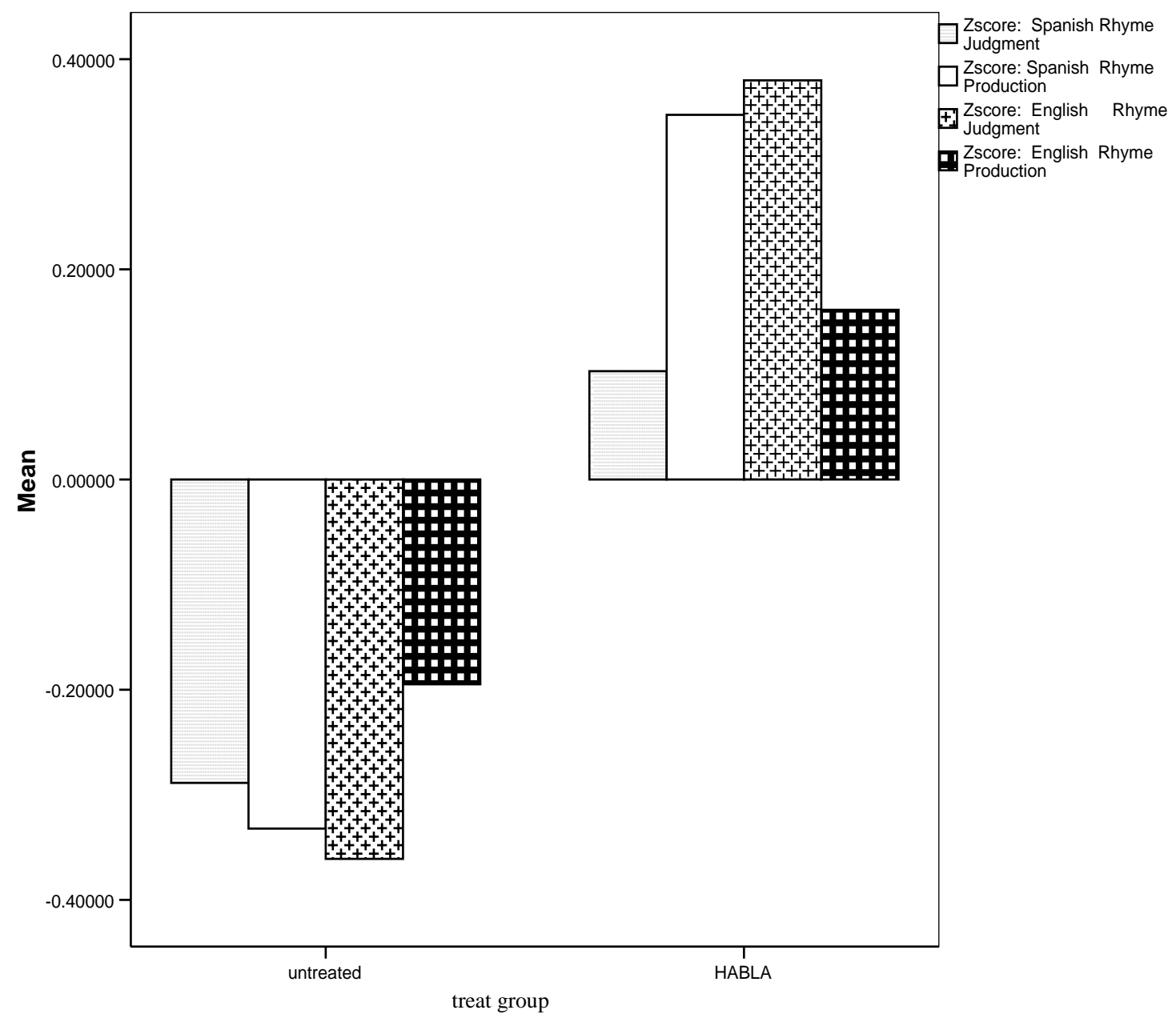

Figure 1. HABLA treatment effects on Spanish and English: kindergarten rhyme judgment and production.

and English, Cohen's $d=.5013$, effect-size $r=.2431$.

Phoneme awareness: Using z-transformations of scores computed separately for each language and each task adapted from Foy and Mann (2001) we examined the effect of treatment group on language (Spanish, English) 
and task (judgment, deletion). There was a main effect of group, $F(1,36)=4.086, M S E=8.68, p<.041$, illustrated in Figure 2, reflecting the superior performance of the HABLA treated children. There is no interaction between group and language and no other effects or interactions were significant (owing to the use of Z-transforms). Computation of treatment effects indicate minimal effects for Spanish phoneme judgment Cohen's $d$ $=.0798$, effect-size $r=.0393$, and Spanish phoneme manipulation Cohen's $d=.1082$, effect-size $r=.0540$, but medium effects for English phoneme judgment, Cohen's $d=.4922$, effect-size $r=.2389$, and English phoneme manipulation, Cohen's $d=.6260$, effect-size $r=.2987$.

Correlation analyses: As a final analysis of the data, a series of bivariate correlations were conducted to examine the relations between the two types of testing and the two languages. For this purpose, rhyme judgment and production were combined into a single score but phoneme manipulation and judgment were kept separate. As seen in Table 4, expressive scores in each language were significantly correlated with receptive scores but the correlations between English and Spanish PLS scores failed to reach significance $(p>.1)$. Spanish expressive scores were correlated at the $p<.05$ level with Spanish rhyme awareness, phoneme judgment, and phoneme manipulation, Spanish receptive scores were correlated with Spanish phoneme manipulation. English expressive scores were correlated with English rhyme awareness, phoneme judgment, and phoneme manipulation, and English receptive scores were correlated with rhyme awareness and phoneme manipulation. Finally, Spanish measures of rhyme and phoneme awareness were significantly intercorrelated as were measures of English rhyme and phoneme awareness, all at the $p<.003$ level or higher. Of the 9 possible correlations between Spanish and English awareness, correlations involve Spanish rhyme awareness failed to reach significance with any of the English versions, but all correlations involving Spanish phoneme awareness were significant at $p<.05$ or

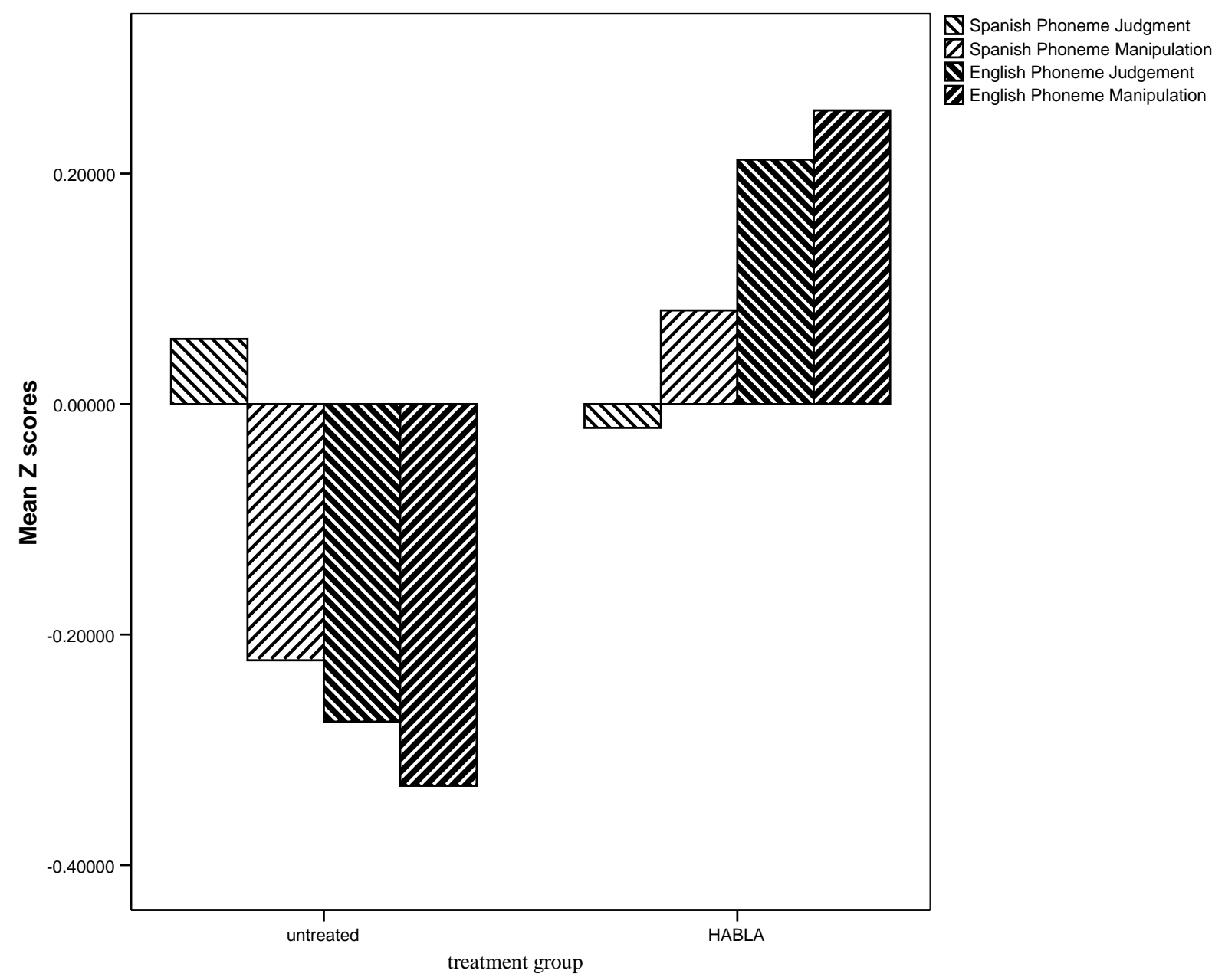

Figure 2. HABLA treatment effects on Spanish and English kindergarten phoneme judgment and manipulation. 
higher as was the correlation between English and Spanish phoneme manipulation.

The parent survey: The questions for the Parent Survey appear in Appendix B. Of the 38 children tested as kindergarteners, 34 had parents who completed and returned the questionnaire, 18 treated and 16 untreated. The responses are summarized in Table 5 and indicate that HABLA participants, on average, were living in a richer literacy environment. Their parents had not received significantly more education, but they read to their children more often at bedtime, $t(33)=3.4, p<.01$, and other times, $t(33)=6.1, p<.01$, they provided access to more books, $t(33)=3.1, p<.01$, and perceived their children as more frequently asking to be read to, $t(33)=4.9, p$ $<.01$. The parents of the treated children were also more likely to report efforts to teach their child to read, $t(33)$ $=4.8, p<.01$, and to print, $t(33)=4.3, p<.01$. Thus the program's goal of increasing home literacy activities appears to be sustained more than one year after the two-year intervention.

\section{Discussion}

Children in low SES families are at increased risk for reading problems due to deficient oral language skills (Honig, 1982; Walker, Greenwood, Hart, \& Carta, 1994) and deficient phonological awareness (Nittrouer, 1996). Some researchers have speculated that the learning of language is constrained by the low values placed upon language in most low-SES sociolinguistic communities (Purcell-Gates, 1995) as well as by parental input that is more directive and immediate (Laosa, 1980, 1982). Lower SES homes are less likely to offer such important home literacy behaviors as shared reading, children's reading materials, age of onset of shared reading (Lonigan, 1994). The quality of parent to child language can also be influenced of ethnicity, gender and maternal language. This study aimed to reduce the widening educational gap that faces Latino students. It used home visitation to enrich the home language and literacy activities during children's early preschool years. Home visits provided parents and children with sustainable Spanish language and literacy materials and were spread over 46 weeks of home visitation. The data indicate significant gains in receptive and expressive Spanish language ability. There is also evidence that the parents sustain their enrichment activities at least one year after the program is completed. Like the immigrant parents studied by Farver, Eppe and Ballon (2006), the Latino immigrant parents in this study were able to make the language and literacy environments in their homes begin to approximate middle-class mainstream culture, The data also provide evidence that as kindergarteners, the treated children kept their Spanish advantage yet also developed an advantage for spoken English and literacy skills.

After each 23-week course of treatment, the Spanish PLS-3 scores of children who participated in the program showed significant gains. The average standardized language scores of treated children rose from pretreatment levels close to the validation sample's average of 90 (Zimmerman et al., 1993) to levels over 100. In contrast, the mean Spanish standard PLS-3 scores for a group of older, untreated children (mean age 47 months) in the community was significantly below the validation sample used to standardize the Spanish PLS-3. The scores of children who participated in HABLA were consistently higher: they did not lose ground and gained as a function of each year's participation. Their average gain of 11 points comes close to the standard deviation of our baseline sample (e.g., 13.5 points) and that of the validation sample (15 points). For the full two-year programs there were medium treatment effects on receptive language and large treatment effects on expressive language.

Table 5. Responses to Parent survey in Kindergarten (lower scores = less activity reported).

\begin{tabular}{ccc}
\hline Question & HABLA treated & $\underline{\text { Control }}$ \\
\hline Maternal Education & $8.9(3.8)$ & $7.7(3.9)$ \\
Paternal Education & $7.0(3.6)$ & $7.4(4.8)$ \\
Age when shared reading began & 26 months $(13.5)$ & 26 months $(15.7)$ \\
Number of children's books & $61-80(0.96)$ & $1.0(2.23)$ \\
Reading at bedtime & $4.0(2.9)$ & $1.8(2.2)$ \\
Reading at other times & $5.6(1.1)$ & $2.7(1.6)$ \\
Child asks to read & $4.8(0.4)$ & $3.2(1.4)$ \\
Parent teaches printing & $4.8(0.5)$ & $2.6(1.4)$ \\
Parent teaches reading & $4.6(0.7)$ & \\
\hline
\end{tabular}


We do not believe that the gains we observed are a function of test familiarity; the pre-treatment and posttreatment testing were separated by at least 7 months, the second and kindergarten by at least 11 months and there was effectively no overlap in questions. We also do not think they are a test artifact due to specific items being for some reason simpler. Treated children achieved higher scores than the pretreatment scores of untreated children the same age (e.g. the first year of treatment for the younger cohort vs. the baseline for the older cohort, the second year of treatment for both cohorts vs. the scores of untreated children). The PLS-3 data in this study suggest that, all else being equal, younger children in this sample have more age-appropriate language skills than older children but both can benefit from intervention. However, both groups had post-treatment scores that were significantly higher than their pre-treatment scores.

The weakness in language skills that we observed in our pre-treatment data is anticipated by the literature: preschool children living in poverty can be impoverished in oral language skills and their extent of disadvantage widens with age (Hart \& Risley, 1995). A similar age-related negative trend was noted in the validation sample (Zimmerman et al., 1993), and is anticipated by research showing that development of a minority language can suffer in the context of bilingual education (Páez, Tabors, \& López, 2007). Conclusions about the language skills of the older untreated children cannot be drawn from PLS-3 data alone as the test was constructed as a translation of the English PLS-3 and is not as a true test of Spanish ability. For the future, all evaluations of HABLA participants will be use the PLS-4, a rigorously standardized and normed instrument developed in Spanish. Data in progress suggest that the intake scores on the PLS-4 are higher, but that significant gains occur after each year.

The data from the children who had participated in at least one year of treatment suggest that a Spanish language home program can promote Spanish language development during and immediately after treatment, possibly restoring disadvantaged children to an age-appropriate level of Spanish language acquisition. The program appears to create a special advantage for expressive language during and right after treatment. What we have further learned from the data for the children we were able to follow into kindergarten is that a Spanish home program can ultimately promote and facilitate both Spanish and English language acquisition in kindergarten. We also observe that parents who had participated in our treatment program reported a greater number of increased shared reading and greater efforts on the part of parents to teach their child about reading and writing.

Among kindergarten children, the HABLA intervention had associated with higher oral language skills in both Spanish and English. It also associated with superior phonological awareness. Children who had been through HABLA achieved significantly higher standard PLS scores in English, as well as in Spanish. As kindergarteners, the treated children surpassed their untreated peers on two different measures of phonological awareness: rhyme and phoneme awareness. They show higher mean scores on Spanish tests of rhyme awareness and phoneme awareness but also show higher mean scores on English tests of rhyme awareness and phoneme awareness.

Both spoken language skills and phonological awareness have been well recognized as particularly critical for the development of reading (see, for reviews: Adams, 1990; Gottardo, Stanovich, \& Siegel, 1996; Foy \& Mann, 2001, 2003; Lyon, 1994; Mahony \& Mann, 1992; Mann, 1984, 1986, 1993, 1998; Mann \& Liberman, 1984; Muter, Hulme, Snowling, \& Taylor, 1998; Snow et al., 1998; Stanovich, 1994; Wagner \& Torgesen, 1987). For alphabetic readers, phoneme awareness is the strongest correlates of reading success because the alphabet is a transcription of phonemes. Phonological awareness is a language activity that requires something above and beyond the skills of listening and speaking. It is a complex skill that derives from interplays among speech abilities and childhood experiences with word play, books and the ABC's. Phoneme awareness is strongly associated with exposure to literacy activities such as the acquisition of letter-sound knowledge and phonics more generally (Mann \& Wimmer, 2002; Morais, Cary, Alegria, \& Bertelson, 1979; Read, Zhang, Nie, \& Ding, 1986). At the same time it is also associated with the development of primary spoken language skills, as the maturational status of phonological representations and vocabulary is critical for a child to take part in the experiences that instantiate phoneme awareness (Elbro, 1996; Fowler, 1991; Foy \& Mann, 2001, 2003; Mann \& Wimmer, 2002, Metsala, 1997). Among four- to six-year-olds, for example, factors in the home literacy environment are associated not only with children's awareness of rhyme and of phonemes, but also with their vocabulary, letter knowledge, and performance on such measures of spoken language skill as nonword repetition, rapid naming skill, phonological distinctness, and auditory discrimination. Both a teaching focus in the home and exposure to reading-related activities are directly associated with phoneme awareness and early reading ability, where exposure to a variety of children's literature supports vocabulary learning, more generally (Foy \& Mann, 2003). 
That an oral language enrichment program for preschoolers can lead to advantages in phonological awareness is consistent with the work of Lonigan (2003) and Foy and Mann (2001) who have shown that children who are advantaged for oral language skills (e.g., the PLS scores) are stronger in emergent literacy skills. The advantage of the HABLA treatment for both English and Spanish phonological awareness as well as the pattern of correlations between English and Spanish skills is consistent with Dickinson, McCabe, Clark-Chiarelli and Wolf (2004) and Quiroga, Lemos-Britton, Mostafapour, Abbott and Berninger (2002), who observed strong cross-linguistic transfer between Spanish and English phonological awareness skills. That we tend to see fewer correlations involving the rhyme tasks may reflect the fact that materials on this task were real words where those on the phoneme awareness tasks also involved some nonce words.

The bilingual gain in kindergarten that we obtained by treating Latino children in a Spanish home visitation program is reminiscent of the results reported by Campos (1995) who reported that Latino children attending a Spanish-only preschool fared better when it came to reading skills in English than those who were in bilingual programs. It also concurs with Baker (2000), Cummins (2000), and Skutnabb-Kangas (2000) and Figuerdo (2006), all of whom emphasize the role of primary language strength in the acquisition of English as a second language by school children.

\section{Conclusion}

The present study adds to the accumulating body of work about school readiness by providing evidence that enriching the oral Spanish language environment in the homes of very young preschoolers, can effectively raise both their Spanish language skills in the preschool years and their English language and literacy achievements in kindergarten. We agree with Kohnert, Yim, Nett, Kan and Duran (2005) that "systematic instruction in a child's home language during the preschool years supports later academic achievement in English (p. 254).” We add that this instruction can occur in the home and appears most effective if it begins around age 2 .

\section{Acknowledgements}

This program was made possible through the generous support of the Children and Families Commission of Orange County, and First Five of California. We would like to express our deep gratitude to the over 50 home visitors who made this program possible, and especially to Lorena Garcia, David Calderon and Maricela Sandoval as well as Rocio Santana, Carolina Rodriguez and Jacqueline Arreola, who completed much of the data entry and the additional testing of the kindergarten cohort. We would also like to thank the families who participated; they let us into their homes and gave us access to their children. We thank Judy Foy for her help with the phonological awareness materials and her comments on the manuscript.

\section{References}

Adams, M.J. (1990). Beginning to Read. Cambridge, MA: MIT Press.

Arnold, D. H., Lonigan, C. J., \& Whitehurst, G. J. (1994). Accelerating Language-Development through Picture Book Reading-Replication and Extension to a Videotape Training Format. Journal of Educational Psychology, 86, 235-243. http://dx.doi.org/10.1037/0022-0663.86.2.235

Baker, C. (2000). A Parents' and Teachers' Guide to Bilingualism (2nd ed.). Clevedon: Multilingual Matters.

Campos, S. J. (1995). The Carpentería Preschool Program: A Long-Term Effects Study. In E. E. Garcia, \& B. McLaughlin (Eds.), Meeting the Challenge of Linguistic and Cultural Diversity in Early Childhood Education (pp. 34-48). New York: Teachers College.

Chaney, C. (1998). Preschool Language and Metalinguistic Skills Are Links to Reading Success. Applied Psycholinguistics, 19, 433-446. http://dx.doi.org/10.1017/S0142716400010250

Cummins, J. (2000). Language, Power, and Pedagogy. Bilingual Children in the Crossfire. Clevedon: Multilingual Matters.

Duursma, E., Romero-Contreras, A., Szuber, P. P., Snow, C., August, D., \& Calderon, M. (2007). The Role of Home Literacy and Language Environment on Bilinguals' English and Spanish Vocabulary Development. Applied Psycholinguistics, 28, 171-190. http://dx.doi.org/10.1017/S0142716406070093

Dickinson, D., McCabe, A., Clark-Chiarelli, N., \& Wolf, A. (2004). Cross-Linguistic Transfer of Phonological Awareness in Low-Income Spanish and English Bilingual Children. Applied Psycholinguistics, 25, 323-347. http://dx.doi.org/10.1017/S0142716404001158 
Elbro, C. (1996). Early Linguistic Abilities and Reading Development: A Review and a Hypothesis. Reading \& Writing, 8, 453-485. http://dx.doi.org/10.1007/BF00577023

Farver, J. M., Eppe, S., \& Ballon, D. (2006). Acculturation and Family Characteristics That Facilitate Literacy Development among Latino Children. In M. H. Bornstein, \& L. R. Cote (Eds.), Acculturation and Parent-Child Relationships: Measurement and Development. Monographs in Parenting Series, Hillsdale, NJ: Erlbaum Press.

Farver, J. A. M., Xu, Y. , Eppe, S. \& Lonigan, C. L. (2006). Home Environments and Young Latino Children’s School Readiness. Early Childhood Research Quarterly, 21, 196-212. http://dx.doi.org/10.1016/j.ecresq.2006.04.008

Figuerdo, L. (2006). Using the Known to Chart the Unknown: A Review of First Language Influence on the Development of English-as-a-Second-Language Spelling Skill. Reading and Writing, 19, 873-905. http://dx.doi.org/10.1007/s11145-006-9014-1

Fowler, A. E. (1991). How Early Phonological Development Might Set the Stage for Phoneme Awareness. In S. Brady, \& D. Shankweiler (Eds.), Phonological Processes in Literacy: A Tribute to Isabelle Y. Liberman (pp. 97-117). Hillsdale, NJ: Erlbaum.

Foy, J. G., \& Mann, V. A. (2001). Does Strength of Phonological Representations Predict Phonological Awareness in Preschool Children? Applied Psycholinguistics, 22, 301-325. http://dx.doi.org/10.1017/S0142716401003022

Foy, J. G., \& Mann, V. A. (2003). Home Literacy Environment and Phonological Awareness in Preschool Children: Differential Effects for Rhyme and Phoneme Awareness. Applied Psycholinguistics, 24, 59-88. http://dx.doi.org/10.1017/S0142716403000043

Gauvain, M., Savage, S., \& McCollum, D. (2000). Reading at Home and at School in the Primary Grades: Cultural and Social Influences. Early Education \& Development, 11, 447-463. http://dx.doi.org/10.1207/s15566935eed1104_5

Gottardo, A., Stanovich, K. E., \& Siegel, L. S. (1996). The Relationship between Phonological Sensitivity, Syntactic Processing and Verbal Working Memory in the Reading Performance of Third Grade Children. Child Psychology, 63, 563-582. http://dx.doi.org/10.1006/jecp.1996.0062

Hart, B., \& Risely, T. R. (1995). Meaningful Differences in the Everyday Lives of Young American Children. Baltimore, MD: Brookes.

Honig, A. S. (1982). Language Environments for Young Children. Young Children, 38, 56-67.

Kamerman, S. B., \& Kahn, A. J. (1995). Starting Right. New York: Oxford University Press.

Kohnert, K., Yim, D., Nett, K., Kan, P. F., \& Duran, K. (2005). Intervention with Linguistically Diverse Preschool Children: A Focus on Developing Home Language(s). Language, Speech and Hearing Services in Schools, 36, 251-263. http://dx.doi.org/10.1044/0161-1461(2005/025)

Laosa, L. M. (1980). Material Teaching Strategies in Chicano and Anglo-American Families: The Influence of Culture and Education on Maternal Behavior. Child Development, 51, 759-765. http://dx.doi.org/10.2307/1129462

Laosa, L. M. (1982). School, Occupation, Culture and Family: The Impact of Parental Schooling on the Parent-Child Relationship. Journal of Educational Psychology, 74, 791-827. http://dx.doi.org/10.1037/0022-0663.74.6.791

Lazar, I., \& Darlington, R. (1982). Lasting Effects of Early Education: A Report from the Consortium of Longitudinal Studies. Monographs of the Society for Research in Child Development, 47, Serial No. 195.

Levenstein, P., Levenstein, S., Shiminski, J. A., \& Stolzberg, J. E. (1998). Long-Term Impact of a Verbal Interaction Program for At-Risk Toddlers: An Exploratory Study of High School Outcomes in a Replication of the Mother-Child Home Program. Journal of Applied Developmental Psychology, 19, 267-285. http://dx.doi.org/10.1016/S0193-3973(99)80040-9

Levenstein, P. and Staff of Verbal Interaction Project (1976). Child’s Behavioiral Traits (CBT). In O. G. Johnson (Ed.), Tests and Measurements in Child Development: Handbook II (Vol. I) San Francisco, CA: Jossey-Bass.

Levenstein, P., Levenstein, S., \& Oliver, D. (2002). First Grade School Readiness of Former Child Participants in a South Carolina Replication of the Parent-Child Home Program. Applied Developmental Psychology, 23, 331-353. http://dx.doi.org/10.1016/S0193-3973(02)00112-0

Lonigan, C. J. (2003). Development and Promotion of Emergent Literacy Skill in Preschool Children At-Risk of Reading Difficulties. In B. R. Foorman (Ed.), Preventing and Remediating Reading Difficulties: Bringing Science to Scale (pp. 23-50). Timonium, MD: York Press.

Lonigan, C. J., \& Whitehurst, G. J. (1998). Relative Efficacy of Parent and Teacher Involvement in a Shared-Reading Intervention for Preschool Children from Low-Income Backgrounds. Early Childhood Research Quarterly, 13, 263-290. http://dx.doi.org/10.1016/S0885-2006(99)80038-6

Lyon, G. R. (1994). Toward a Definition of Dyslexia. Annals of Dyslexia, 45, 3-27.

Mach, E. J., \& Johnston, C. (1982). A Comparison of the Mother-Child Interactions of Younger and Older Hyperactive and Normal Children. Child Development, 53, 1371-1381. http://dx.doi.org/10.2307/1129028 
Mahony, D. L, \& Mann, V. A. (1992). Using Children’s Humor to Clarify the Relationship between Linguistic Awareness and Future Reading Ability. Cognition, 45, 163-186. http://dx.doi.org/10.1016/0010-0277(92)90028-G

Mann, V. A. (1998). Language Problems: A Key to Early Reading Problems. In B. Y. L. Wong (Ed.), Learning about Learning Disabilities (2nd ed., pp. 163-201). San Diego, CA: Academic Press.

Mann, V. A. (1993). Phoneme Awareness and Future Reading Ability. Journal of Learning Disabilities, 26, $259-269$. http://dx.doi.org/10.1177/002221949302600406

Mann, V. A. (1986). Phonological Awareness: The Role of Reading Experience. Cognition, 24, 65-92. Also published under the same title in: P. Bertelson (1987). The Onset of Literacy, 1987. Cambridge, MA: MIT Press.

Mann, V. A. (1984). Longitudinal Prediction and Prevention of Early Reading Difficulty. Annals of Dyslexia, 34, 117-136. http://dx.doi.org/10.1007/BF02663616

Mann, V. A., \& Liberman, I. Y. (1984). Phonological Awareness and Verbal Short-Term Memory: Can They Presage Early Reading Problems? Journal of Learning Disabilities, 17, 592-599. http://dx.doi.org/10.1177/002221948401701005

Mann, V., \& Wimmer, H. (2002). Phoneme Awareness and Pathways to Literacy: A Comparison of German and American Children. Reading \& Writing, 15, 653-682. http://dx.doi.org/10.1023/A:1020984704781

Metsala, J. (1997). Spoken Word Recognition in Reading Disabled Children. Journal of Educational Psychology, 89, 159169. http://dx.doi.org/10.1037/0022-0663.89.1.159

Morais, J., Cary, L., Alegria, J., \& Bertelson, P. (1979). Does Awareness of Speech as a Sequence of Phones Arise Spontaneously? Cognition, 7, 323-331. http://dx.doi.org/10.1016/0010-0277(79)90020-9

Muter, V., Hulme, C., Snowling, M., \& Taylor, S. (1998). Segmentation, Not Rhyming, Predicts Early Progress in Learning to Read. Journal of Experimental Child Psychology, 71, 3-27. http://dx.doi.org/10.1006/jecp.1998.2453

National Reading Council (2001). Putting Reading First: Helping your Child Learn to Read. Washington DC: The Partnership for Reading through the National Institute for Literacy (NIFL) and the National Institute for Child Health and Human Development (NICHD), U.S. Department of Education.

Nittrouer, S. (1996). The Relation between Speech Perception and Phonemic Awareness: Evidence from low SES Children and Children with Chronic OM. Journal of Speech and Hearing Research, 39, 1059-1070.

Páez, M. M., Tabors, P. O., \& López, L. M. (2007). Dual Language and Literacy Development of Spanish-Speaking Preschool Children. Journal of Applied Developmental Psychology, 28, 85-102.

http://dx.doi.org/10.1016/j.appdev.2006.12.007

Purcell-Gates, V., McIntyre, E., \& Freppon, P. A. (1995). Learning Written Storybook Language in School: A Comparison of Low SES Children in Skills-Based and Whole-Language Classrooms. American Educational Research Journal, 32, 659- 685. http://dx.doi.org/10.3102/00028312032003659

Quiroga, T., Lemos-Britton, Z., Mostafapour, E., Abbott, R. D., \& Berninger, V. W. (2002). Phonological Awareness and Beginning Reading in Spanish-Speaking ESL First Graders: Research into Practice. Journal of School Psychology, 40, 85111. http://dx.doi.org/10.1016/S0022-4405(01)00095-4

Raver, C. C., \& Knitzer, J. (2002). Ready to Enter: What Research Tells Policy Makers about Strategies to Promote Social and Emotional School Readiness among Three- and Four-Year-Olds. Washington DC: National Center for Children in Poverty.

Read, C., Zhang, Y., Nie, H., \& Ding, B. (1986). The Ability to Manipulate Speech Sounds Depends on Knowing Alphabetic Writing. Cognition, 24, 31-44. http://dx.doi.org/10.1016/0010-0277(86)90003-X

Seneschal, M., Le Fevre, J., Thomas, E., \& Daley, K. (1998). Differential Effects of Home Literacy Experiences on the Development of Oral and Written Language. Reading Research Quarterly, 33, 96-116. http://dx.doi.org/10.1598/RRQ.33.1.5

Skutnabb-Kangas, T. (2000). Linguistic Genocide in Education-Or Worldwide Diversity and Human Rights? Mahwah, NJ: Lawrence Erlbaum Associates.

Snow, C. E. (1991). The Theoretical Basis for Relationships between Language and Literacy in Development. Journal of Research in Childhood Education, 6, 5-10. http://dx.doi.org/10.1080/02568549109594817

Stanovich, K. E. (1994). Annotation: Does Dyslexia Exist? Journal of Child Psychology, 49, 44-68.

Wagner, R. K., \& Torgesen, J. K. (1987). The Nature of Phonological Processing and Its Causative Role in the Acquisition of Reading Skills. Psychological Bulletin, 101, 192-212. http://dx.doi.org/10.1037/0033-2909.101.2.192

Walker, D., Greenwood, C., Hart, B., \& Carta, J. (1994). Prediction of School Outcomes Based on Early Language Production and Socioeconomic Factors. Child Development, 65, 606-621. http://dx.doi.org/10.2307/1131404

Walley, A. C. (1993). The Role of Vocabulary Development in Children’s Spoken Word Recognition and Segmentation Ability. Developmental Review, 13, 286-350. http://dx.doi.org/10.1006/drev.1993.1015

Zimmerman, I. L., Steiner, V. G., \& Pond, R. E. (1993). Preschool Language Scale-3, Spanish Edition. San Antonio, TX: 
The Psychological Corporation.

Zimmerman, I. L., Steiner, V. G., \& Pond, R. E. (2002). Preschool Language Scale (4th ed.). San Antonio, TX: The Psychological Corporation.

Zimmerman, I. L., \& Castilleja, N. F. (2005). The Role of a Language Scale for Infant and Preschool Assessment. Mental Retardation and Developmental Disabilities Research Reviews, 11, 238-246. http://dx.doi.org/10.1002/mrdd.20078

\section{Appendix}

\section{Materials for Parent Survey:}

1. What is the mother's highest level of education:

2. What is the father's highest level of education: ___ grades grades

3. How old was your child when you first started reading picture books to him/her?

4. How many children's books are available in your household?
None $1-20$
$21-40$
$41-60$
$61-80$
more? (estimate

5. How often do you, or other members of the family read to your child in a typical week:

a. At bedtime?

$\begin{array}{lcccccccc}\begin{array}{l}\text { never } \\ \text { b. Other times? }\end{array} & \text { once } & 2 & 3 & 4 & 5 & 6 & 7 \text { times } & \text { more? (estimate__ } \\ \text { never } & \text { once } & 2 & 3 & 4 & 5 & 6 & 7 \text { times } & \text { more? (estimate__ }\end{array}$

6. During a typical week how often does your child ask to be read to?
Never 1
2
3
4
5 Very often

7. During a typical week, how often do you engage in the following activities?

a. I teach my child to print words:
1
2
3
4
5
Never

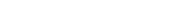
Often

b. I teach my child to read:

$\begin{array}{lllll}1 & 2 & 3 & 4 & 5\end{array}$

Never Often

8. How many children's books are available in your household
None
1 - 20
21 - 40
$41-60$
61 - 80
more? (estimate 